\title{
La revocatoria al mandato ¿un mecanismo de participación ciudadana o un mecanismo de oposición partidiaria?
}

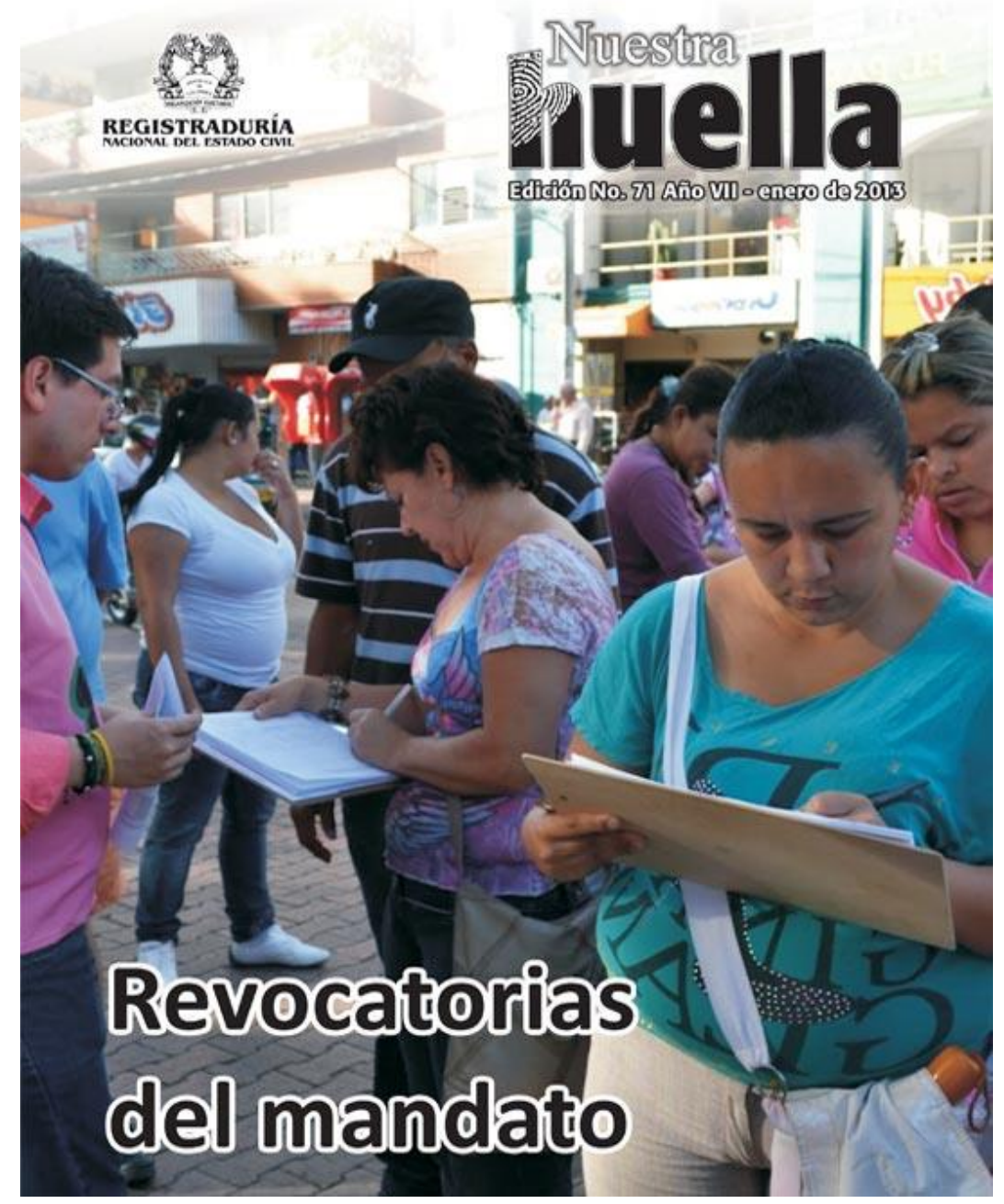

(Fuente: Registraduría Nacional del Estado Civil, 2013)

Por: Dulfary Calderón Sánchez[1]

La participación no solo debe ser vista como el poder que se otorga a los ciudadanos únicamente en las urnas para elegir representantes políticos en un periodo electoral determinado, sino que debe trascender a espacios de seguimiento de las acciones que llevan a cabo los gobernantes, así mismo debe ser entendido como un elemento articulador de cohesión social para la toma decisiones que afecta su entorno colectivo. Para Merino (1996) implica participar en la administración de los recursos, en las decisiones públicas y en esas acciones que influye en la esfera social. 
En este contexto, la Constitución de 1991 y la Ley 134 de 1994, generaron como herramienta de control político que los ciudadanos puedan revocar el mandato a los alcaldes y Gobernadores antes de culminar su periodo de gobierno, permitiendo de esta manera que se ejerza una veeduría por parte de los ciudadanos al percibir o denotar el incumplimiento de sus planes de Desarrollo y de la falta de gobernabilidad en el territorio.

De esta manera, este instrumento de control permitió la organización de la ciudadanía por medio de movimientos civiles, para impulsar este tipo de iniciativas que logren cumplir con los requisitos legales para convocar a nuevas elecciones.

En Colombia, se han realizado "166 intentos -165 para burgomaestres y uno por mandatario seccional- pero de ellos solo 50 llegaron a las urnas y 116 no han superado la etapa de recolección de firmas. Ningún funcionario elegido por votación popular ha sido revocado" (El país, 2017).

Sin embargo, la ciudadanía aún recurre a este mecanismo como única salida para poder revocar un alcalde o un Gobernador, quizás porque aún se cree en la institucionalidad del Estado o porque existe un conflicto de intereses de quienes acuden a ella. Actualmente, en Colombia se lleva un proceso de 70 funcionarios electos que están "amenazados" por este tipo de mecanismo; es el caso de los alcaldes de Bogotá, Cartagena, Bucaramanga, Barrancabermeja, Neiva, Quindío, Pereira, El Socorro (Santander), San Benito (Sucre) y la Gobernación del Quindío, entre otros.

En este contexto, pareciera que el problema de la ingobernabilidad y el incumplimiento de los programas de Gobierno están siendo más controlados por los ciudadanos, dado a que se presenta una organización para lograr un fin y se confía en la repuesta por parte de las instituciones en este caso del Consejo Nacional Electoral - CNE- sea llamar de nuevo a las urnas. Sin embargo, se debe analizar que no todo es participación, si se tiene en cuenta que la percepción ciudadana sirve para alimentar las fuerzas de oposición que encuentran detrás de una revocatoria del mandato, es decir, allí hallan el espacio perfecto para lograr revocar al gobernante y posicionarse de nuevo en las regiones, donde quizás alguna vez tuvieron presencia como partidos y que por motivos coyunturales no lograron perpetuar su maquinaria política.

En este contexto, se podría pensar que dado a que existe esa injerencia de los partidos políticos y de los movimientos organizados para la recolección de firmas que son necesarias para revocar el mandato, ya estaría incluido la participación ciudadana dado a que estas colectividades son la suma de intereses individuales. Sin embargo, su legitimidad y reconocimiento social no representa necesariamente el interés de todos, para Nohlen (2006) la participación es definida como el acto de tomar parte, en donde subyace una concepción instrumental y una normativa.

Es así, que más allá de los resultados y la posición que se tenga respecto a si realmente existe el nivel de participación ciudadana para este tipo de mecanismos de control, o si por el contrario unos pocos logran generar esa percepción de participación por medio de las organizaciones que pueden estar manejadas por los intereses de unos partidos o personajes políticos, la revocatoria es un instrumento que debe contar con la legalidad y legitimidad 
necesaria, para creer que aún el ciudadano puede ser un tomador de decisiones más allá de unas simples elecciones públicas.

[1] Profesor titular de la asignatura de Gobernabilidad y políticas públicas, Líder línea de investigación y codirectora del Observatorio de Seguridad y Políticas Públicas para el posconflicto de la Facultad de Gobierno y Relaciones Internacionales de la Universidad Santo Tomás. Candidata a PHD en Ciencia Política de la Universidad Complutense de Madrid, Politóloga de la Universidad Nacional, Magister en Gestión y política pública de la Universidad de Chile. Dulfarycalderon@usantotomas.edu.co

\section{Referencias}

Merino, M. (1996). La participación Ciudadana en la Democracia Ilpes, CEPAL, Quito.

El País (11 de enero de 2017). ¿Será el 2017 el año de las revocatorias de mandatos?. Obtenido de http://www.elpais.com.co/colombia/sera-el-2017-el-ano-de-las-revocatoriasde-mandatos.html

Nohlen, Dieter (2006), Diccionario de ciencia política, México, Editorial Porrúa. 